\title{
Utility and health-related quality of life measures in adult Colombian patients with solid tumours
}

\author{
Rafael Chaves-Cardona ${ }^{1}$, Martín Romero Prada ${ }^{1,2}$, Maria Victoria Ocampo ${ }^{1}$, Duván Gallo², Lina María Gómez² and Natalia Clavijo \\ ${ }^{1}$ Jorge Tadeo Lozano University, Calle 127a N 70h-42, Bogotá, Colombia \\ ${ }^{2}$ Proyéctame Group, Transversal 60\#124-20 Oficina 210, Colombia
}

\section{Abstract}

According to a 2020 report, the World Health Organization explained how, in 20 years, the prevalence of cancer cases will increase by $60 \%$ worldwide. In lower-middle-income countries, this figure will be $74.07 \%$. Therefore, the authors propose a series of recommendations, such as how to address both traditional health indicators and the psychosocial environment, to improve the health system. The objective of this study is to demonstrate the impact of cancer on the quality of life (QoL) and health status of oncology patients in Colombia. An observational cross-sectional study using patient reported outcomes tools, such as European Organization for Research and Treatment of Cancer (EORTC) Quality of Life of Cancer Patients (QLQ-C30) and EuroQoL-5 dimensions questionnaire-3 levels (EQ5D-3L), was carried out. The information of 356 people was compiled. They were contacted by patient associations. The results were analysed using descriptive and inferential statistics, using ordinary least squares methodology. For the EORTC QLQ-C30, overall health status was 66.05 (95\% confidence interval: 63.78-68.32), on the functional scales, emotional and social function were the two scales with the lowest ratings (71.57 and 71.77), without any representative differences. For the EQ5D-3L, the average utility was 0.70 (Standard deviation: 0.20 ); $50 \%$ of people had a utility between 0.63 and 0.82 . The analysed population was most affected in the following areas: financial difficulties, insomnia, anxiety, depression and emotional functioning, establishing the need for future interventions and the creation of public policies that generate a better QoL for patients.

Keywords: quality of life, patient reported outcomes, cancer

\section{Introduction}

According to a 2018 report by the Cuenta de Alto Costo (the Colombian fund for high-cost diseases), the reported prevalence of cancer in the Columbian population was 275,348 , of which 37,630 were new cases. This was an overall increase of $15.82 \%$ compared to 2017. Additionally, $95.1 \%$ of the prevalent cases were of an invasive nature and $4.9 \%$ were in situ cancers, a similar behaviour to the incident cases reported [1]. The prevalence of invasive cancer has increased from 393.3 in 2016; 446.9 per 100,000 inhabitants in

Correspondence to: Martín Romero Prada Email: martin.romero@proyecta-me.com

ecancer 2021, 15:1240

https://doi.org/10.3332/ecancer.2021.1240

Published: 03/06/2021

Received: 01/12/2020

Publication costs for this article were supported by ecancer (UK Charity number 1176307).

Copyright: (c) the authors; licensee ecancermedicalscience. This is an Open Access article distributed under the terms of the Creative Commons Attribution License (http:// creativecommons.org/licenses/by/3.0), which permits unrestricted use, distribution, and reproduction in any medium, provided the original work is properly cited. 
2017; to 531 per 100,000 inhabitants in 2018 [1, 2]. In a 2020 report, the World Health Organization (WHO) explained how, in the next two decades, the prevalence of cancer will increase by $60 \%$ worldwide, and in lower-middle-income countries, such as Colombia, an increase of $74.07 \%$ could occur [3].

Beyond the WHO preventative measures for the reduction of incident cases, this body sets out as its main recommendation, improvement in the provision of services for oncology patients [3] including creating policies appropriate to each country [4], which should address not only traditional health indicators but also the psychosocial environment [5]. Whatever the cause for the increase in this condition, it has made cancer a priority for Colombia's public health policies. In this regard, the government has set out actions for the comprehensive care of cancer patients, framed within the 10-year plan for the control of cancer 2012 to 2021 [6], and in law 1384 of 2010 [7], which sets out that it is essential to improve the quality of life (QoL) of patients. Despite having the objective of providing adequate information on cancer for decision-making, the National Cancer Observatory (ONC Colombia) does not address the areas of physical, mental and social well-being in their entirety. They do little to study the results in depth. Consequently, their actions related to the improvement of the QoL for cancer patients are limited. They also fail to mention the results to patients as a main source of information [8].

Conceptually, health-related quality of life (HRQOL) facilitates an understanding of the patient's well-being from their own point of view. This enables evaluation of any changes resulting from medical interventions or health systems [9]. Thereby, demonstrating its utility for describing the impact of the disease on patients' lives [10]. In the same way, the concept of patient reported outcomes (PRO) is the information provided by the patient, explaining the symptoms associated with their health status and how they affect his or her HRQOL [11]. In other words, HRQOL is a concept that includes multiple dimensions representing the patient's overall perception of the effects of the disease and treatment of different aspects of their physical, psychological and social life. Such information provided by the patient will be the basis for the proper design of the care pathway, especially for patients with advanced cancer [12].

In this sense, the systematic implementation of questionnaires that evaluate the PRO of cancer patients could contribute to the comprehensive care proposed by the national government. This is especially the case in the care of patients with advanced cancer, such as that developed in palliative care models, where an organised intervention for predominant symptoms improves HRQOL. Therefore, as an initial step towards the development of these strategies, this study proposes to seek to demonstrate the utility of this type of questionnaire for patient care in Colombia [10, 11].

There are some scientific publications evaluating QoL of patients with cancer in Colombia. Castillo-Ávila et al [13] carried out one such study on a group of people with cervical cancer. They were subject to the application of PRO tools, such as the European Organization for Research and Treatment of Cancer (EORTC) Quality of Life of Cancer Patients (QLQ-C30) and the EORTC QOL-Quality of Life of Cervical Cancer. This showed the most affected aspects of QoL related to health were: social activities (51.9\%), functional and physical status, effects of treatment on family life (48.1\%) and financial difficulties as a result of the disease (47.2\%) [13]. In Antioquia, Salas and Grisales [14] using the WHOQOL BREF (World Health Organization Quality of Life, abbreviated version) demonstrated that socioeconomic factors, level of education, family support and cultural and religious beliefs affect the QoL of women being treated for breast cancer. The study carried out by Gaviria et al identified significant levels of anxiety and depression in oncology patients through the use of PRO tools [15]. Mejía-Rojas et al [16] identified how the effects of treatment for patients with breast cancer were the main aspects that led to a deterioration in the QoL, using tools such as QLQ-C30 and Quality of Life Breast Cancer.

This study forms part of the PROCáN strategy, a support for the implementation of public health activities, focused on measuring the health status of cancer patients. It is used to generate valid information on critical issues requiring intervention, and to then plan multidimensional interventions that improve the QoL of these patients. As a starting point for the design of the strategy, it was necessary to have an initial measurement of the perceived outcomes for cancer patients and the changes in respect of their conditions. This study aims to demonstrate the impact of cancer on QoL and health status in Colombia, the utility of this type of questionnaire for the care of cancer patients, and especially for those in the advanced stages of the disease. The questionnaires are expected to provide useful information to develop proposals and actions for public policy for the care of cancer patients in the country. 


\section{Methodology}

A joint strategy, called PROCáN, was developed by a group of social and health science researchers, with the support of cancer patient associations, in different cities of the country, and was coordinated by the Fundación Simmon (a Columbian cancer foundation). This joint strategy developed a cross-sectional study to evaluate the perceived QLQ-C30 in Colombia. It was approved by the ethics committee.

The Spanish versions of the European Organization for Research and Treatment of Cancer (EORTC) Quality of Life of Cancer Patients (QLQ-C30) [17] and the EuroQoL-5 dimensions questionnaire-3 levels (EQ5D-3L) [18] questionnaires were used to assess QoL and health status. From a review of the literature, it was identified that the EORTC QLQ-C30 is one of the most widely used questionnaires, because it can be used for patients with any type of cancer; in addition, there is a validated version for use in Colombia [17]. This is a multidimensional questionnaire with 30 questions, which evaluate five aspects of QoL (physical, role, cognitive, emotional and social), three symptom scales (fatigue, pain, nausea and vomiting), a global health status scale (QoL) and single items assessing additional, commonly reported symptoms (dyspnoea, loss of appetite, insomnia, constipation and diarrhoea) [19]. The five aspects are assessed on a scale of 1-100, where 1 reflects a lower perception of health and 100 a higher perception. On the symptom scale, the assessment is also from 0 to 100 but inversely, 1 indicates that the symptom is not present and 100 represents a poor presentation of the symptom. Assessment of the EORTC QLQ-C30 was carried out using the recommendations from the EORTC data centre [19].

The second tool used was the EQ5D-3L questionnaire [18] in Spanish validated for Colombia, which was developed by the EuroQoL group [20]. It is used to identify health status, measure utility and evaluate HRQOL. It consists of two components: the first evaluates five dimensions: mobility, self-care, usual activities, pain/discomfort and anxiety/depression. Each of the dimensions is evaluated at three levels of severity: 1 = no problems; 2 = some problems and 3 = extreme problems. This scale gives a five digit number as a result, which describes the health status of the patient. It is possible to obtain up to 243 possible health statuses, with 11,111 being the best possible health status with a utility of 1 , and 33,333 the worst possible status with a utility of -0.101 [21]. The second component is a visual analogue scale, in which the patient rates his or her health status, with 1 being the worst state imaginable and 100 the best. To assess health status using the EQ5D-3L, the recommended scoring for Colombia was used, obtained by Zarate et al [21].

The use of physical versions of the two questionnaires for this study in quantities greater than the estimated sample size, was authorised by the licence owners. The existence of the studies and their corresponding validation for Colombia were previously verified [22].

The sample size was estimated with a confidence level of 99\%, the standard deviation taken from previous studies was 20 [23], and the data accuracy obtained from \pm 3 of the HRQOL measurements. An estimate was obtained using the calculation of a finite population of an estimated 198,798 [24] cancer patients in Colombia in 2016, with an expected loss of 15\%, which gave 346 patients. The sample was gathered by patient associations who brought together patients in different cities around the country (Bogotá, Cali, Santa Marta, Valledupar and Villavicencio). This was coordinated by the Fundación Simmon. Only adult patients with a solid-type cancer and a confirmed diagnosis of cancer were included. Acceptance for inclusion in this study was validated through signed informed consent. The target population for this study participated freely and voluntarily, without any coercion over their responses; they were free not to answer any questions if they did not wish to do so.

The survey, which included characteristics of the patient and their disease, and the established questionnaires, was carried out by health personnel, who had previously received training on the objective of the study and the application of the tools. It was carried out during June and July 2018. The information was collected on paper. Then, it was transcribed into a single database. This process was validated by two of the researchers to avoid the risk of losing information and to ensure the quality of the data obtained.

The data on the characteristics of the population and their disease were analysed with descriptive statistics using the mean and standard deviation. Inferential statistics were also used for characteristics. Cls of 95\% were taken and the scores obtained were compared with the QoL tools using ordinary least squares regression methodology; values of $p<0.05$ were taken to be statistically significant. The statistical software package Stata Version 14 was used for the study [25]. 


\section{Results}

A total of 355 people were surveyed. The data collection process was coordinated by the Fundación Simmon. The respondents had an average age of 56.12 years (Standard deviation (SD): \pm 14.3 years) and an interquartile range of $47-67$ years. $69.01 \%$ of the patients were female, with 245 women taking part; 2.3 women were surveyed for every man participating (Table 1).

The most frequent types of cancer were breast, other and colon; nine individuals reported having more than one type of cancer, similar to that reported in the literature. Most patients were being treated with chemotherapy and radiotherapy. It was highlighted that $5.67 \%$ of the respondents did not know their status at the time of the survey (Table 2). To show the time that had elapsed from diagnosis of the disease to the survey date, the results are presented based on the information provided by the respondents. $82.53 \%$ of the population had a diagnosis date, so it was possible to identify how long the patient had had the disease, excluding 24 patients who did not remember their diagnosis date, and 60 patients who failed to record it fully (Table 2).

The results relating to the global health scale using EORTC QLQ-C30, from 0 to 100, with 100 being the best perception of health, measured overall health status as 66.05 (95\% confidence interval (Cl): 63.78-68.32). When functional aspects were evaluated, emotional and social functions had the lowest scores (71.57 and 71.77), without any representative differences between the functional scales. Within the symptom analysis, which is rated inversely, that is to say, the higher the score, the worse the perception of health, financial difficulties and insomnia were those that attracted the worst scores (58.2 and 36.76) (Table 3).

The analysis of the health status of those surveyed according to the responses of the EQ5D-3L tool took into account 338 respondents, as they fully responded to this part of the survey. It was found that the average utility was 0.70 (SD: 0.20 ); $50 \%$ of people had utilities between 0.63 and 0.82 .

Depending on the different demographics and clinical characteristics, where QoL was concerned, there was a relationship between the average scores found by the EQ5D-3L and EORTC QLQ-C30 tools. Regarding analysis by gender, it was shown that with both tools, women scored worse in both the general components and the specific scales; this difference being statistically significant only for the utility of the

EQ5D-3L. Additionally, the worst average score was among cancer patients with a pre-existing comorbidity, in those whose cancer had progressed, and those who did not know what their current status was, compared to those who had improved, this was a statistically significant difference $(p<0.05)$. No significant differences were identified by age, type of treatment in the last 6 months or by duration of disease (Table 4).

\section{Discussion}

The results of this study demonstrate the utility of making a parametric assessment of cancer symptoms by showing the differences between patients. Additionally, the health situation of patients with more advanced stages of the disease was more compromised by the severity of the symptoms.

Studies previously conducted in Colombia, such as that of Bermúdez et al [22], where QoL was evaluated using the QLQ-C30 questionnaire in a cancer population which attended a foundation in the city of Bucaramanga, came up with an average score of $60 \pm 9.3(95 \% \mathrm{Cl}$ : 57.01-62.99). This was in accordance with the data obtained in this study, which identified an overall score of 66.05 (95\% Cl: 63.78-68.32).

Finck et al [23], using the EORTC QLQ-C30 on 1,500 Colombians in the general population, found an average score for overall health status of 77.1 (SD: 18.5). When this result is compared to the QoL measurement obtained in cancer patients included in this study, the decrease due to the disease is more than 10 points (an average of $66.05,95 \% \mathrm{Cl}: 63.8-68.3$ ). The functional and symptom scales showed that the population with cancer was more affected than the general population. The general population had functional scale scores above 87 , while in patients with cancer it was cognitive function that scored the highest with 76.8 (73.93-79.66). The symptom with the greatest impact on the general population was fatigue, with a score of 14.0 (SD: 18.4), while in the cancer population it was dyspnoea (average 13.68,95\% $\mathrm{Cl}$ : 10.89-16.46). In addition, participants in this analysis experienced more financial difficulties, reaching an average of 52.8 ( $95 \% \mathrm{Cl}$ : 48.68-56.92), while in the general population the average score is 7.2. By seeing these differences, the sensitivity of the questionnaire can be demonstrated by identifying the extent of complications that cancer patients experience compared to the general population, which is the objective of this research. 
Table 1. Socio-demographic characteristics of the surveyed population.

\begin{tabular}{|c|c|c|}
\hline Characteristic & $n$ & $\%$ \\
\hline \multicolumn{3}{|l|}{ Age } \\
\hline $18-44$ years & 72 & 20.28 \\
\hline $45-59$ years & 128 & 36.06 \\
\hline $60-69$ years & 90 & 25.35 \\
\hline 70 and older & 65 & 18.31 \\
\hline \multicolumn{3}{|l|}{ Gender } \\
\hline Female & 245 & 69.01 \\
\hline Male & 108 & 30.42 \\
\hline Unknown & 2 & 0.56 \\
\hline \multicolumn{3}{|l|}{ Marital status } \\
\hline Married & 134 & 37.75 \\
\hline Divorced & 24 & 6.76 \\
\hline Other & 15 & 4.23 \\
\hline Single & 87 & 24.51 \\
\hline Civil partner & 70 & 19.72 \\
\hline Widow(er) & 25 & 7.04 \\
\hline \multicolumn{3}{|l|}{ Level of education } \\
\hline Postgraduate & 7 & 1.97 \\
\hline Professional & 32 & 9.01 \\
\hline Technical & 52 & 14.65 \\
\hline Baccalaureate & 123 & 34.65 \\
\hline Primary school & 120 & 33.80 \\
\hline None & 20 & 5.63 \\
\hline No information & 1 & 0.28 \\
\hline \multicolumn{3}{|l|}{ Household } \\
\hline Partner/children & 262 & 73.80 \\
\hline Alone & 25 & 7.04 \\
\hline Friends & 1 & 0.28 \\
\hline Other/family & 65 & 18.31 \\
\hline No information & 2 & 0.56 \\
\hline \multicolumn{3}{|l|}{ Employment status } \\
\hline Seeking work & 8 & 2.25 \\
\hline Student & 7 & 1.97 \\
\hline Unemployed & 138 & 38.87 \\
\hline Pensioner & 37 & 10.42 \\
\hline Works at home & 93 & 26.20 \\
\hline Worker & 69 & 19.44 \\
\hline No information & 3 & 0.85 \\
\hline
\end{tabular}


Table 2. Clinical characteristics of the respondents.

\begin{tabular}{|c|c|c|}
\hline Characteristic & $N$ & $\%$ \\
\hline \multicolumn{3}{|l|}{ Type of cancer } \\
\hline Colorectal & 35 & 9.62 \\
\hline Cervical & 31 & 8.52 \\
\hline Gastric or stomach & 21 & 5.77 \\
\hline Skin & 13 & 3.57 \\
\hline Lung & 19 & 5.22 \\
\hline Prostate & 31 & 8.52 \\
\hline Other & 67 & 18.41 \\
\hline Breast & 147 & 40.38 \\
\hline \multicolumn{3}{|c|}{ Presence of comorbidities } \\
\hline Yes & 145 & 40.84 \\
\hline No & 210 & 59.15 \\
\hline \multicolumn{3}{|l|}{ Current treatment } \\
\hline Chemotherapy & 241 & 66.39 \\
\hline Radiotherapy & 37 & 10.19 \\
\hline Surgery & 3 & 0.83 \\
\hline Other & 30 & 8.26 \\
\hline None & 48 & 13.22 \\
\hline \multicolumn{3}{|c|}{ Treatment within the last 6 months } \\
\hline Chemotherapy & 192 & 56.30 \\
\hline Radiotherapy & 72 & 21.11 \\
\hline Surgery & 40 & 11.73 \\
\hline Other & 15 & 4.40 \\
\hline None & 22 & 6.45 \\
\hline \multicolumn{3}{|c|}{ Time since diagnosis of disease } \\
\hline Less than 1 year & 13 & 4.44 \\
\hline 1 year & 150 & 51.19 \\
\hline 2 years & 51 & 17.41 \\
\hline 3 years & 26 & 8.87 \\
\hline 4 years & 13 & 4.44 \\
\hline 5 years or more & 40 & 13.65 \\
\hline \multicolumn{3}{|l|}{ Stage of the disease } \\
\hline Controlled & 177 & 50.14 \\
\hline Has improved & 96 & 27.20 \\
\hline Has progressed & 60 & 17.00 \\
\hline Unknown & 20 & 5.67 \\
\hline
\end{tabular}


Table 3. QoL assessment using EORTC QLQ-C30. Bold values are statistically significant to 95\% interval confidence.

\begin{tabular}{|l|c|c|}
\hline \multicolumn{1}{|c|}{ Dimension } & EORTC QLQ-C30 & Cl \\
\hline Overall health status & 66.05 & $(63.78-68.32)$ \\
\hline Functional scale & 73.81 & $(71.56-76.04)$ \\
\hline Physical & 74.72 & $(72.15-77.29)$ \\
\hline Role & 75.45 & $(72.29-78.59)$ \\
\hline Emotional & 71.57 & $(68.74-74.40)$ \\
\hline Cognitive & 76.80 & $(73.93-79.66)$ \\
\hline Social & 71.77 & $(68.46-75.07)$ \\
\hline Symptoms scale & 29.02 & $(26.88-31.14)$ \\
\hline Fatigue & 35.81 & $(32.96-38.64)$ \\
\hline Nausea and vomiting & 16.48 & $(13.90-19.04)$ \\
\hline Pain & 31.49 & $(28.26-34.71)$ \\
\hline Dyspnoea & 13.68 & $(10.89-16.46)$ \\
\hline Insomnia & 36.76 & $(33.16-40.36)$ \\
\hline Loss of appetite & 29.46 & $(25.86-33.05)$ \\
\hline Constipation & 22.10 & $(18.95-25.23)$ \\
\hline Diarrhoea & 17.77 & $(14.91-20.61)$ \\
\hline Financial difficulties & 52.80 & $(48.68-56.92)$ \\
\hline
\end{tabular}

Table 4. EORTC QLQ-C30-EQ5D-3L: Descriptive and inferential analysis.

\begin{tabular}{|c|c|c|c|c|c|c|c|c|}
\hline \multirow[b]{4}{*}{ Characteristic } & & & & & & & & \\
\hline & \multirow{2}{*}{\multicolumn{2}{|c|}{ EQ5D-3L }} & \multicolumn{6}{|c|}{ EORTC QLQ-C30 } \\
\hline & & & \multicolumn{2}{|c|}{ Overall health status } & \multicolumn{2}{|c|}{ Functional scale } & \multicolumn{2}{|c|}{ Symptoms scale } \\
\hline & Avg (SD) & $p$-value & Avg (SD) & $p$-value & Avg (SD) & $p$-value & $\begin{array}{l}\text { Avg } \\
\text { (SD) }\end{array}$ & $p$-value \\
\hline \multicolumn{9}{|l|}{ Gender } \\
\hline Female & $0.68(0.2)$ & - & $64.45(22.39)$ & - & 72.02 (22.03) & - & $30.51(20.8)$ & - \\
\hline Male & $0.76(0.2)$ & 0.24 & $69.7(19.37)$ & 0.414 & 78.03 (19.27) & 0.569 & $25.43(19.04)$ & 0.934 \\
\hline \multicolumn{9}{|l|}{ Age } \\
\hline $18-44$ years & $0.71(0.18)$ & - & 65.96 (18.94) & - & 73.94 (18.47) & - & $27.8(18.86)$ & - \\
\hline $45-59$ years & $0.7(0.19)$ & 0.447 & $67.72(21.67)$ & 0.453 & $74.36(21.86)$ & 0.493 & 28.55 (19.85) & 0.252 \\
\hline $60-69$ years & $0.7(0.22)$ & 0.543 & $65.56(22.49)$ & 0.982 & $74.18(22.16)$ & 0.614 & $29.77(20.92)$ & 0.167 \\
\hline 70 and older & $0.7(0.22)$ & 0.497 & $63.59(23.64)$ & 0.933 & 72.03 (23.09) & 0.698 & $30.24(22.61)$ & 0.329 \\
\hline \multicolumn{9}{|c|}{ Treatment within the last 6 months } \\
\hline Chemotherapy & $0.70(0.2)$ & 0.961 & $64.69(20.4)$ & 0.431 & 74.07 (19.77) & 0.493 & $31.19(20.43)$ & 0.661 \\
\hline Radiotherapy & $0.69(0.2)$ & 0.512 & $65.49(19.79)$ & 0.663 & $73.50(23.05)$ & 0.620 & $30.44(23.17)$ & 0.262 \\
\hline Surgery & $0.68(0.19)$ & 0.344 & $58.97(20.62)$ & 0.193 & $68.05(17.82)$ & 0.226 & $32.87(21.13)$ & 0.557 \\
\hline Other & $0.71(0.22)$ & 0.882 & $64.49(25.77)$ & 0.787 & $72.47(26.74)$ & 0.575 & $28.92(23.54)$ & 0.207 \\
\hline None & $0.71(0.24)$ & 0.314 & $66.67(28.05)$ & 0.143 & $67.61(26.81)$ & 0.866 & $27.12(23.33)$ & $0.017^{\mathrm{a}}$ \\
\hline
\end{tabular}


Table 4. EORTC QLQ-C30-EQ5D-3L: Descriptive and inferential analysis. (Continued)

\begin{tabular}{|c|c|c|c|c|c|c|c|c|}
\hline \multicolumn{9}{|l|}{ Disease duration } \\
\hline Less than 1 year & $0.68(0.27)$ & - & $64.74(21.29)$ & - & $65.46(32.7)$ & - & $35.31(28.94)$ & - \\
\hline 1 year & $0.70(0.18)$ & 0.764 & 67.39 (20.39) & 0.972 & $74.91(19.86)$ & 0.371 & $28.38(19.67)$ & 0.413 \\
\hline 2 years & $0.72(0.21)$ & 0.439 & $66.17(22.86)$ & 0.997 & $74.96(19.89)$ & 0.334 & $29.53(19.2)$ & 0.602 \\
\hline 3 years & $0.67(0.22)$ & 0.764 & $66.03(23.56)$ & 0.658 & $73.54(22.46)$ & 0.506 & $29.43(23)$ & 0.468 \\
\hline 4 years & $0.77(0.19)$ & 0.217 & $67.31(25.79)$ & 0.995 & $79.66(17.45)$ & 0.055 & 24.9 (19.09) & 0.198 \\
\hline 5 years or more & $0.71(0.16)$ & 0.200 & $62.92(24.75)$ & 0.835 & $72.89(22.44)$ & 0.153 & $27.99(17.64)$ & 0.144 \\
\hline \multicolumn{9}{|c|}{ Presence of comorbidities } \\
\hline Yes & $0.67(0.2)$ & $0.002^{a}$ & $65.1(22.41)$ & 0.148 & $70.65(22.60)$ & $0.008^{a}$ & 31.81 (20.13) & $0.006^{a}$ \\
\hline No & $0.73(0.2)$ & - & $66.71(21.24)$ & - & $75.98(20.40)$ & - & 27.09 (20.39) & - \\
\hline \multicolumn{9}{|l|}{ Stage of the disease } \\
\hline Has improved & $0.75(0.16)$ & - & 71.79 (19.51) & - & 78.88 (19.13) & - & $24.47(17.83)$ & - \\
\hline Controlled & $0.75(0.18)$ & 0.628 & $68.8(19.61)$ & 0.280 & 77.96 (17.98) & 0.878 & $\begin{array}{c}24.7 \\
(17.2)\end{array}$ & 0.518 \\
\hline Has progressed & $0.52(0.22)$ & $0.000^{\mathrm{a}}$ & $52.26(24.31)$ & $0.000^{a}$ & 57.15 (23.73) & $0.000^{\mathrm{a}}$ & $45.15(22.55)$ & $0.000^{\mathrm{a}}$ \\
\hline Unknown & $0.63(0.19)$ & $0.032^{\mathrm{a}}$ & $55(22.2)$ & $0.001^{\mathrm{a}}$ & 64.15 (24.91) & 0.177 & $40.36(23.52)$ & $0.007^{a}$ \\
\hline \multicolumn{9}{|l|}{ Type of cancer } \\
\hline Colorectal & $0.75(0.19)$ & - & $69.89(21.48)$ & - & 79.21 (19.54) & & $25.29(19.32)$ & - \\
\hline Cervical & $0.63(0.29)$ & 0.258 & $61.41(24.69)$ & 0.496 & 68.77 (27.91) & 0.327 & $35.47(26.89)$ & 0.251 \\
\hline Gastric or stomach & $0.72(0.27)$ & 0.942 & $72.91(20.06)$ & 0.936 & $79.36(18.86)$ & 0.967 & $29.02(18.65)$ & 0.621 \\
\hline Skin & $0.82(0.15)$ & 0.59 & $78.84(13.01)$ & 0.140 & 83.85 (14.69) & 0.496 & $16.28(16.71)$ & $0.048^{a}$ \\
\hline Lung & $0.68(0.24)$ & 0.970 & $52.78(30.52)$ & 0.057 & $64.89(29.60)$ & 0.317 & $39.77(28.56)$ & 0.508 \\
\hline Prostate & $0.76(0.22)$ & 0.661 & $68.82(15.06)$ & 0.638 & 77.60 (20.77) & 0.939 & 22.69 (12.61) & 0.356 \\
\hline Other & $0.67(0.22)$ & 0.283 & $63.25(23.88)$ & 0.413 & $66.89(24.11)$ & 0.142 & $34.09(23.36)$ & 0.278 \\
\hline Breast & $0.70(0.14)$ & 0.614 & $66.32(20.27)$ & 0.938 & 75.39 (17.87) & 0.493 & 27.40 (17.21) & 0.730 \\
\hline
\end{tabular}

The $p$-value was obtained using the ordinary least squares regression methodology. Avg, Average; SD, Standard deviation

${ }^{a}$ Statistically significant differences, value of $p<0.05$

Regarding international studies, Hinz et al [26] conducted a QoL study with the EORTC QLQ-C30 tool among 2,059 German patients with different types of cancer. They found an average reduction in the functional scale of 11.8 points compared with the general German population (the average for the cancer population was 74.8, SD: 19.3), with a difference of 9.2 points for the symptom scale (the average for the cancer population was 20.8, SD: 16.6). When comparing it with the results of this study, there are similarities in the average score on the functional scale, being 73.81 (95\% Cl: 71.56-76.04) and for the symptom scale, being 29.02 (95\% Cl: 26.88-31.14). For the functional scales, it was shown for both the German population and the patients analysed in this study, that the emotional aspect was affected the most, with values of 69.8 (SD: 24.9) and 71.57 (95\% Cl: 68.74-74.40), respectively. The most important difference between the two studies was in the symptom scale, with the highest score being for fatigue in the German population (35.6, SD: 25.6), while in this study financial difficulty scored the highest (52.8 - 48.68 - 56.92). 
In Latin America, Torrecilla et al [27] identify the needs of patients in clinical practice, from a perspective that includes psycho-oncology, optimising health services by correctly addressing the needs of 80 women diagnosed with cancer, including the measurement of QoL using the EORTC QLQ-30; financial difficulties were identified as one of the most affected items, as in this analysis. Similarly, the study by Salas and Grisales [14] in Antioquia, which evaluated QoL of patients with breast cancer using the WHOQOL-100 scale, found that women with the disease had a lower score in the physical, psychological and social domains, as well as a lower overall score. This demonstrates that the approach to oncology patients goes beyond the provision of health services and highlights the need to implement treatment strategies focused on the needs of the patients, addressing emotional aspects and the financial burden.

For this study, using both the EORTC QLQ-C30 and the EQ5D-3L scales, the anxiety, depression and emotional function aspects were those most affected. The Colombian health system does not provide an adequate response to these issues within its care routes. Among the surveyed patients, financial difficulties produced the worst assessment in terms of outcome. This highlights the need for specific new studies to determine, in more detail, the perceived financial toxicity, as this can vary in context from pocket money to the perception of social financial disaster, in addition to the corresponding effects of financial distress on the patient's daily life, among other things.

Cancer, defined in Colombia as a catastrophic disease due to the technical complexity and high cost of its treatment, and the low costeffectiveness of the interventions [28], generates a worse perception in patients' QoL, a situation that is reflected in this and in other published studies [14, 22]. Furthermore, a differing impact on the QoL of people with comorbidities and with progressive disease is shown, demonstrating that there are people with specific needs who must be considered when implementing additional measures to improve their health condition.

Current care models have focused on the definition of curative interventions, diagnostic methods and medication. This study demonstrates the importance of incorporating follow-up and interventions for symptoms that have not normally been recognised as indicators in patients with cancer, such as insomnia or financial toxicity. The aim is to promote the use of QoL measures using the patient as a primary source of information; to identify the most affected dimensions in patients with interesting pathology; to develop damage limitation processes; and to develop follow-up actions within the Colombian social security system that help evaluate the proposed strategies.

Regarding the limitations of this study, it should be taken into account that the information obtained is self-reported by patients who suffer from cancer and there is no detailed clinical description of the stages of the disease for each person. On the other hand, the objective of this analysis was not to find differences by specific phases or types of treatment. Only a descriptive approach was taken, whereby, information can be made known in the near future. Additionally, in the development of this study, it was impossible to use a questionnaire designed specifically for the Colombian population. This made it possible that dimensions that would have been of vital importance for Colombian patients, in accordance with their socio-cultural context, were not taken into account or evaluated. However, the EORTC QLQ-C30 questionnaire was used in the study, which was partly validated by Finck et al [23], who assessed the scale on the general population, aged over 18 years, in the major cities of Colombia.

It should be noted that within this study, it is possible that there is no representative sample by socioeconomic status, since cancer patients above level 5 (very high socioeconomic level) do not seek care in organisations such as foundations. However, considering that this population makes up less than $10 \%$, the data presented in this analysis enables us to focus on the creation of public policy interventions which protect the majority of citizens.

The application of PRO tools succeeds in identifying areas for intervention, enabling their adjustment to the needs of the patient and developing their respective follow-up. Kaasa et al [29] explain the use of results reported by patients to improve symptom control, achieve better physical and mental health and make better use of health services, since there is no agreement that standardises priorities for the management of the palliative care patient. It is also pertinent to continue conducting future studies that address the QoL and other palliative needs of this population. In this study, it was demonstrated how patients who had stated that the cancer had progressed, had a lower QoL when compared to those who said that the cancer had improved, was under control or did not know, by recording lower average measures for EQ5D-3L, the overall health status and functional scale of the EORTC; and higher average measurements for the symptoms scale of the same PRO tool. This demonstrates the importance of intervention for these patients. One of the intervention strategies put forward by WHO [14] to improve the patient's QoL, alleviating physical, psychological, social or spiritual suffering [13] is to include the palliative needs of oncology 
patients [12]. This study demonstrates the benefit of its application to cancer patients at different stages of the disease, and demonstrates how its routine use, as part of clinical activity, would enable better targeting of actions, in groups where the presence of symptoms is even more sensitive, as could be the case in patients with advanced disease [16, 30].

In addition, it shows how cancer negatively impacts patients' QoL when viewed from the overall QoL perspective; such as the different dimensions that can be assessed when using PRO tools, as well as providing important information on care, it also demonstrated their sensitivity at different stages of the disease.

\section{Conclusions}

Patients diagnosed with cancer experience deterioration in their QoL, presenting with effects in areas such as financial difficulties, insomnia, anxiety, depression and emotional function, in addition to the symptoms related to the disease and its treatment. The use of specific assessment tools, such as the EORTC QLC30, enables a parametric identification of multidisciplinary care and standardisation of habitual use, which could be the subject for public policy.

\section{List of abbreviations}

HRQOL, Health-related quality of life; SD, Standard deviation; EORTC, European Organization for Research and Treatment of Cancer; EQ5D-3L, EuroQoL-5 dimensions questionnaire-3 levels; Cl, Confidence interval; WHO, World Health Organization; PRO, Patient reported outcome; QLQ-C30, Quality of life of cancer patients; WHOQOL BREF, World Health Organization quality of life, abbreviated version; WHOQOL-100, World Health Organization quality of life.

\section{Ethics approval and consent to participate}

This study was approved by the Riesgo de Fractura (fracture risk) ethics committee, study number 30983 . For all participants, written consent was obtained in accordance with the study protocol.

\section{Conflicts of interest}

The researchers participating in this research project have not declared any conflicts of interest.

\section{Funding}

The PROCáN project received funding for its implementation through a grant from MSD laboratories. However, this did not influence the design, analysis or results of the study.

\section{Acknowledgements}

Special thanks to the Fundación Simmon, its director and the entire team for their support in the development of the research, especially for bringing together and coordinating the patient groups fundamental to this study; and to the patients who dedicated time and showed enthusiasm in responding to the surveys. Thanks to Lina María Huérfano for her collaboration in the implementation phase of this research and for all the contributions made. 


\section{References}

1. Fondo Colombiano de Enfermedades de Alto Costo, Ministerio de Salud y la Protección Social (2019) Situación del cancer en la poblacion antendida en el SGSSS de Colombia 2018 Fondo Colomb Enfermedades Alto Costo 1(1) 37-39

2. Fondo Colombiano de enfermedades de alto costo (2017) Cuenta de alto. Situación del cáncer en la poblacion adulta atendida en el SGSSS de Colombia

3. Organización Mundial de la Salud (OMS) (2020) La OMS expone en líneas generales los pasos para evitar la muerte 7 millones de personas por cancer (Geneva: Organización Mundial de la Salud (OMS))

4. Organización Mundial de la Salud (OMS) (2004) Improving the quality of health care Virtual Mentor 6(6) 253-254

5. Organización Mundial de la Salud (OMS) (2016) World Cancer Report 2014 Adv Nutr 7(2) 418-419 PMID: 26980827 PMCID: 4785485

6. Ministerio de Salud y Protección Social (2013) Plan Decenal de Salud Pública, PDSP, 2012 - 2021 (Bogota: Ministerio de Salud y Protección Social)

7. Congreso de la República de Colombia (2010) Ley 1384 de 2010 (Ley Sandra Ceballos. Diario Oficial)

8. Minisiterio de Salud y Protección Social (2018) Observatorio Nacional de Cáncer (Washington: ONC Colomb) pp 1-59

9. Fayers PM and Machin D (2007) Quality of life: the assessment, analysis and interpretation of patient-reported outcomes Quality of Life: The Assessment, Analysis and Interpretation of Patient-Reported Outcomes 2nd edn (Hoboken: Wiley) pp 404.

10. Urzúa MA (2010) Calidad de vida relacionada con la salud: elementos conceptuales Rev Med Chil 138(3) 358-365 https://doi. org/10.4067/S0034-98872010000300017

11. Deshpande PR, Rajan S, and Sudeepthi BL, et al (2011) Patient-reported outcomes: a new era in clinical research Perspect Clin Res 2(4) 137-144 https://doi.org/10.4103/2229-3485.86879 PMID: 22145124 PMCID: 3227331

12. Hoerger M, Greer JA, and Jackson VA, et al (2018) Defining the elements of early palliative care that are associated with patientreported outcomes and the delivery of end-of-life care J Clin Oncol 36(11) 1096-1102 https://doi.org/10.1200/JCO.2017.75.6676 PMID: 29474102 PMCID: 5891131

13. Castillo-Ávila IY, Canencia-Padilla J, and Zurbarán-Lamadrid M, et al (2015) Quality of life in women with cervical cancer, Cartagena (Colombia), 2012 Rev Colomb Obstet Ginecol 66(1) 22-31 https://doi.org/10.18597/rcog.4

14. Salas Zapata C and Grisales Romero H (2010) Calidad de vida y factores asociados en mujeres con cáncer de mama en Antioquia, Colombia Rev Panam Salud Pública https://doi.org/10.1590/S1020-49892010000700002

15. Gaviria A, Riveros F, and Japcy M, et al (2007) Calidad de vida relacionada con la salud, afrontamiento del estrés y emociones negativas en pacientes con cáncer en tratamiento quimioterapéutico Psicol desde el Caribe 20 50-75

16. Mejía-Rojas ME, Contreras-Rengifo A, and Hernández-Carrillo M (2020) Calidad de vida en mujeres con cáncer de mama sometidas a quimioterapia en Cali, Colombia. Bioméd 40(2) 349-361 https://doi.org/10.7705/biomedica.4971

17. Sánchez R, Venegas M, and Otero J, et al (2009) Adaptación transcultural de dos escalas para medir la calidad de vida en pacientes con cáncer en Colombia: EORTC QLQ-C30 y QLQ-BR23 Rev Colomb Cancerol 13(4) 205-212 https://doi.org/10.1016/S01239015(09)70119-2

18. EuroQol Group (1990) EuroQol--a new facility for the measurement of health-related quality of life Health Policy 16(3) 199-208 https:// doi.org/10.1016/0168-8510(90)90421-9 PMID: 10109801 
19. Fayers P, Aaronson N, and Bjordal K (2001) EORTC QLQ-C30 Scoring Manual (Brussels: Eortc)

20. Herdman M, Badia X, and Berra S, et al (2001) El EuroQol-5D: una alternativa sencilla para la medición de la calidad de vida relacionada con la salud en atención primaria Aten Primaria 28(6) 425-429 https://doi.org/10.1016/S0212-6567(01)70406-4 PMID: 11602124 PMCID: 7684037

21. Zarate V, Kind P, and Chuang LH (2008) Hispanic valuation of the EQ-5D health states: a social value set for Latin Americans Value Health 11(7) 1170-1177 https://doi.org/10.1111/j.1524-4733.2008.00349.x PMID: 18489516

22. Cruz Bermudez HF, Moreno Collazos JE, and Angarita Fonseca A (2013) Medicion de la calidad de vida por el cuestionario QLQ - C30 en sujetos con diversos tipos de cancer de la ciudad de bucaramanga-Colombia Enferm Glob 12(30) 294-303 https://doi.org/10.6018/ eglobal.12.2.160351

23. Finck C, Barradas S, and Singer S, et al (2012) Health-related quality of life in Colombia: reference values of the EORTC QLQ-C30 Eur J Cancer Care (Engl) 21(6) 829-836. https://doi.org/10.1111/ecc.12000

24. Cuenta de alto costo (2016) Situación del cáncer en la población adulta atendida en el sgsss de Colombia p 274.

25. (c) Copyright 1996-2019 StataCorp LLC. Stata 14.

26. Hinz A, Mehnert A, and Dégi C, et al (2017) The relationship between global and specific components of quality of life, assessed with the EORTC QLQ-C30 in a sample of 2019 cancer patients Eur J Cancer Care (Engl) 26(2) https://doi.org/10.1111/ecc.12416

27. Torrecilla N, Casari L, and Rivas J (2016) Afrontamiento y calidad de vida en mujeres pacientes oncológicas 8(3) 1-16

28. Ministerio de Salud y Protección Social (1994) Resolucion Numero 5261 De 1994 1994(Agosto 5):1-138

29. Kaasa S, Loge JH, and Aapro M, et al (2018) Integration of oncology and palliative care: a Lancet Oncology Commission Lancet Oncol 19(11) e588-e653 https://doi.org/10.1016/S1470-2045(18)30415-7 PMID: 30344075

30. Gaertner J, Wolf J, and Voltz R (2012) Early palliative care for patients with metastatic cancer Curr Opin Oncol 24(4) 357-362 https:// doi.org/10.1097/CCO.0b013e328352ea20 PMID: 22476189 